\title{
RIT Logo based Slotted PLPCMA Multi-Band Patch Antenna
}

\author{
Venkatesh Nuthan Prasad, Eshwar Dhanush Gowda, Krishnappa Indira, Ananya Kodikula, \\ Bhavan B. Rao \\ Department of Electronics \& Communication Engineering, Ramaiah Institute of Technology \\ MSR Nagar, MSRIT Post, Bengaluru 560054 \\ India
}

Received: August 5, 2021. Revised: January 21, 2022. Accepted: February 7, 2022. Published: March 8, 2022.

\begin{abstract}
A compact Printed Log-Periodic Curvilinear Monopole Array (PLPCMA) antenna having a Defected Ground Plane (DGP) is proposed and examined. The proposed array of curvilinear monopoles is designed on a FR-4 substrate having a dielectric constant of 4.4. The designed antenna is multi-band operated having its resonance in the regions of $S$ band $(2 \mathrm{GHz}$ to $4 \mathrm{GHz}), X$ band $(8 \mathrm{GHz}$ to $12 \mathrm{GHz}$ ) and $\mathrm{C}$ band $(4 \mathrm{GHz}$ to $8 \mathrm{GHz})$. The design reveals Voltage Standing Wave Ratio (VSWR) lesser than 1.5 has been achieved at resonating frequencies $2.49 \mathrm{GHz}, 3.28 \mathrm{GHz}, 6.84 \mathrm{GHz}$ and $8.36 \mathrm{GHz}$ with fractional bandwidth of $4.02,3.66,50.58$ and 41.39 percentages respectively. The presented antenna exhibits unidirectional end-fire radiation pattern with peak realized gain of 7 . 1145dBi.The measured results depicts that PLPCMA antenna has good -10dB impedance bandwidth of $158 \%$ from $1.58 \mathrm{GHz}$ to $15 \mathrm{GHz}(9.49: 1)$ and suits for WiFi/WIMAX UWB applications.
\end{abstract}

Keywords-Broadband; Curvilinear; Antenna gain; Log periodic; Patch antenna; Microstrip; Slot

\section{INTRODUCTION}

$\mathrm{C}^{\mathrm{u}}$ urvilinear geometrical structures are the topic of intrigue in the design of micro strip patch antennas for wireless communication. The performance of patch antenna is limited by narrow bandwidth which limits their use in broadband systems. Several techniques are employed to enhance the bandwidth such as log-periodic linear array technique [1]- [4], slotted patch [5], [6] and defected ground structures [7]- [9].

Several logo type antennas are available in the literature which includes symbols, university emblems, logos, letters and so on [10]-[15]. Progress in designing of Printed Log-Periodic Monopole Array (PLPMA) antennas on the dielectric substrates, led to the development of efficient high gain antennas operating in broadband range suitable for several wireless applications ranging from Wi-Fi, Wireless Local Area Network (WLAN) to Bluetooth, RADAR, Speed detectors and so on. This work emphasizes the study of a novel PLPCMA antenna. The curvilinear patch is designed to resemble the logo. The necessary design aspects are summarized, Section III discusses about the assessment of simulated outcomes for several slot positioning in the ground plane. The antenna is found to be multi-band operated with a realized antenna gain from $4.0 \mathrm{dBi}$ to $7.11 \mathrm{dBi}$. Lastly, Section IV negotiates the conclusion.

\section{LITERATURE REVIEW}

W. Li, K. L. Chung and Y. Li [13] describe in their paper the modal significance and modal radiation pattern of different modes. They also highlight the future application in product advertisement. According to the author E.Dhanush Gowda [24] the use of taper feed and impedance matching to the source importance, The use of slot and its role in minimize the return lose characteristics is summarized in there paper. $\mathrm{Z}$. Mahlaoui, E. Antonino-Daviu, M. Ferrando-Bataller paper presents a procedure that entails the combination of two techniques to reduce the patch antenna size and thus yield a wide tunable frequency range. Adding a slot in the ground plane aids in moving the basic frequency of the antenna from $7.273 \mathrm{GHz}$ down to $4.267 \mathrm{GHz}$ by ensuring the fundamental geometrical design of the antenna is maintained. By altering the varactor values, successive bands in the range of $4.65 \mathrm{GHz}$ to $6.18 \mathrm{GHz}$ are acquired [26]. A wideband multiple microstrip dipole antenna (MMDA) with dual polarization is presented in this paper. The patches are placed beneath the radiator, at right angles to one another and are fabricated on a $0.8 \mathrm{~mm}$ thick FR-4 substrate. Tacitly, a solitary dipole would give rise to a particular linear polarization. Although, multiple well organized dipoles may radiate and harmonize a new slant linear polarization as proposed by the authors Zhou, Z., Wei, 
Z., Tang [27].

\section{PROPOSED WORK}

The introduced antenna model as illustrated in figure 1(a) has 6 curvilinear monopoles [3] whose width and length are assorted $\log$ periodically as a function of the scaling factor $\tau$ given in equation (1). The inter-monopole distances are affirmed and computed using the spacing factor $\sigma$ by means of equation (2). All the elements including boom are made curvilinear to mimic the logo as shown in figure 2(c).

$\frac{1}{\tau}=\frac{L_{n}}{L_{n-1}}=\frac{D_{n}}{D_{n-1}}=\frac{W_{n}}{W_{n-1}}$

$D_{n}=2 \sigma L_{n}$

where, $n$, signifies any integer lying in the range $(1 \leq n \leq 6), L_{n}$ and $W_{n}$ are the width and length of $n^{\text {th }}$ monopole respectively. $D_{n}$ is the distance from the nth monopole and $(n-1)^{s t}$ monopole element. Table I describes the presented antenna's design parameters.

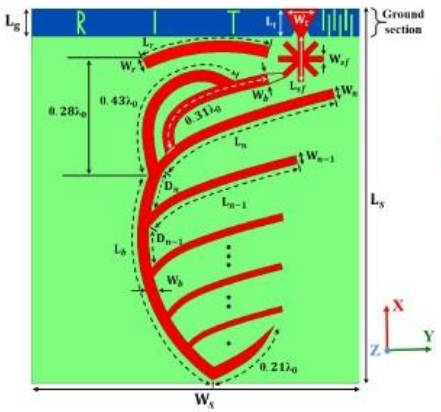

(a)

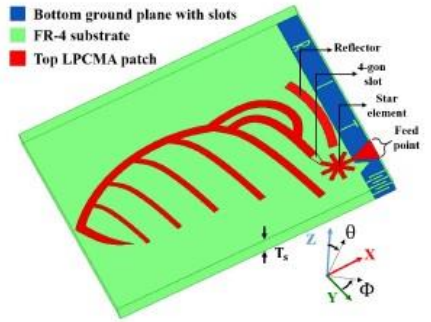

(b)

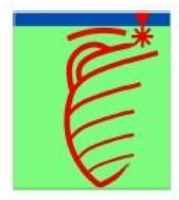

(c)

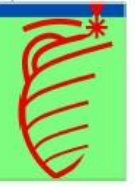

(d)

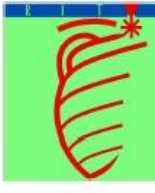

(e)

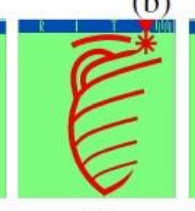

(f)

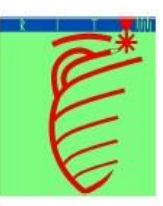

(g)
Figure 1. The introduced antenna's geometry in (a) Described measurements (b) 3-D view (c) Partial ground plane (d) V shaped defect in ground (e) DGP with RIT slot (f) DGP with RIT and meander slots (g) DGP with RIT and meander slots along with polygon (4-gon) slot in curvilinear boom.

$\mathrm{W}_{\mathrm{g}}$

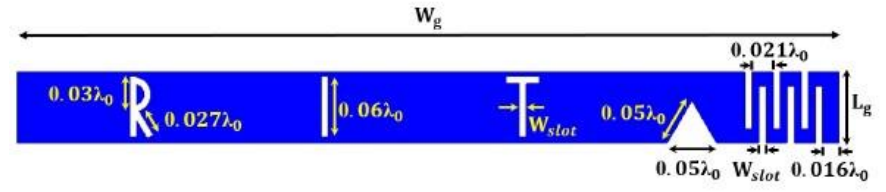

(a)

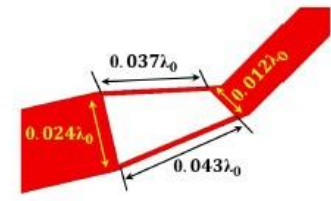

(b)

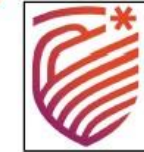

RAMAIAH Institute of Technology
Figure 2. Design dimension of (a) DGP with RIT and meander slots (b) Polygon (4-gon) slot in the curvilinear boom (c) Institutional logo used as design reference.

The copper patch is substantiated on the FR-4 (glass reinforced epoxy laminate) substrate having dielectric constant $\varepsilon_{r}=4.4$. The effective permittivity $\varepsilon_{e_{1}}$ for $\left(\frac{W_{t}}{T_{s}}>1\right)$ and $\varepsilon_{e_{2}}$ for $\left(\frac{W_{s f}}{T_{s}}<1\right)$ [20] are computed with the use of equation (3) and (4) examining the wider section's width of triangular taper $W_{t}$ and width of star element $W_{s f}$ respectively.

$\varepsilon_{e_{1}}=\frac{\varepsilon_{r}+1}{2}+\frac{\varepsilon_{r}-1}{2}\left\lfloor\frac{1}{\sqrt{1+\frac{12 * T_{s}}{W_{t}}}}\right\rfloor$

Table I. Design parameters of Antenna

\begin{tabular}{|c|l|l|l|}
\hline Part & \multicolumn{1}{|c|}{ Description } & \multicolumn{1}{c|}{ Value } & Unit \\
\hline$c$ & Velocity of Light & $3 \times 10^{8}$ & $\mathrm{~m} / \mathrm{s}$ \\
\hline$f_{0}$ & Center Frequency & 8.36 & $\mathrm{GHz}$ \\
\hline$\lambda_{0}$ & Wavelength at $f_{0}$ & 35.8852 & $\mathrm{~mm}$ \\
\hline$\tau$ & Scaling Factor & 0.865 & - \\
\hline$\sigma$ & Spacing Factor & 0.12 & - \\
\hline$f_{\min }$ & Lower Frequency & 2.0 & $\mathrm{GHz}$ \\
\hline$f_{\max }$ & Upper Frequency & 3.0 & - \\
\hline$N$ & Number of Elements & 6 & $\mathrm{~mm}$ \\
\hline$T_{s}$ & Substrate Thickness & 1.6 & $\mathrm{~mm}$ \\
\hline$W_{s}$ & Width of Substrate & 29.1492 & $\mathrm{~mm}$ \\
\hline$L_{s}$ & Length of Substrate & 33.2888 & $\mathrm{~mm}$ \\
\hline$W_{g}$ & Width of Partial Ground & 29.1492 & $\mathrm{~mm}$ \\
\hline$L_{g}$ & Length of Partial Ground & 2.5 & $\mathrm{~mm}$ \\
\hline$W_{t}$ & Taper Width at Broader Side & 3.083 & $\mathrm{~mm}$ \\
\hline$L_{t}$ & Length of the Tapered Feed & 2.5 & $\mathrm{~mm}$ \\
\hline$W_{s f}$ & Width of Star Element & 0.5 & $\mathrm{~mm}$ \\
\hline$L_{s f}$ & Length of Star Element & 4.0 & $\mathrm{~mm}$ \\
\hline$W_{s l o t}$ & Width of Meander Slot & 0.25 & $\mathrm{~mm}$ \\
\hline$W_{r}$ & Curvilinear Reflector Width & 1.0 & $\mathrm{~mm}$ \\
\hline$L_{r}$ & Curvilinear Reflector Length & 11.6061 & $\mathrm{~mm}$ \\
\hline$W_{b}$ & Curvilinear Boom Width & 1.0 & $\mathrm{~mm}$ \\
\hline$L_{b}$ & Curvilinear Boom Length & 20.5103 & $\mathrm{~mm}$ \\
\hline$L_{6}$ & Length of the Longest Element & 16.8751 & $\mathrm{~mm}$ \\
\hline$L_{1}$ & Length of the Shortest & 7.5814 & $\mathrm{~mm}$ \\
\hline & Element & & \\
\hline
\end{tabular}

$$
\varepsilon_{e 2}=\frac{\varepsilon_{r}+1}{2}+\frac{\varepsilon_{r}-1}{2}\left\lfloor\frac{1}{\sqrt{1+\frac{12 * T_{s}}{W_{t}}}}+\frac{1}{25}\left[1-\left(\frac{W_{s f}}{T_{s}}\right)\right]^{2}\right\rfloor
$$

The impedance variation along source-taper-boom section is as shown in Fig. 3(a). The $W_{t}$ is computed and configured to co-ordinate with $50 \Omega$ source impedance $Z_{0}$. The crosssectional impedance at the broader section of the taper $Z_{1}$ and 
the impedance between star element strip and taper transition $Z_{s f}$ are computed using (5) and (6) respectively.

$$
\begin{aligned}
& Z_{1}=\frac{120 \pi}{\sqrt{\varepsilon_{e_{1}}\left[\frac{W_{t}}{T_{s}}+1.393+\frac{2}{3} \ln \left(\frac{W_{t}}{T_{s}}+1.444\right)\right]}} \\
& Z_{s f}=\frac{60}{\sqrt{\varepsilon_{e_{2}}}} \ln \left\lfloor\frac{8 T_{s}}{W_{s f}}+\frac{W_{s f}}{4 T_{s}}\right\rfloor
\end{aligned}
$$

The length of the taper $L_{t}$ is also subsidized for impedance matching. The effect of taper's reflection coefficient [20] is computed using equation (7) which ensures to be a function of $L_{t}$.

$$
\Gamma(\theta)=\left|\frac{1}{2} \ln \left(\frac{Z_{s f}}{Z_{1}}\right)\left[\frac{\sin \left(\frac{\beta L_{t}}{2}\right)}{\frac{\beta L_{t}}{2}}\right]\right|^{2} \mid e^{-j \beta L_{t}}
$$

where, $\Gamma(\theta)$ refers to the reflection coefficient and $\beta$ refers to the phase constant of the triangular tapered feed line. The length of the curved boom $L_{b}$ and length of the reflector $L_{r}$ are calculated using arc length equation (8) as given in figure $3(\mathrm{~b})$.

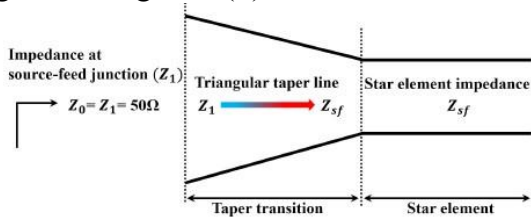

(a)

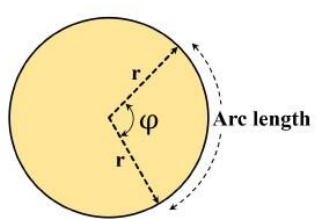

(b)
Figure 3(a). Triangular taper impedance matching between a star element strip and the source (b) Arc length calculation using central angle $\varphi$ and radius $r$.

Arc Length $=\left(\frac{\pi}{180}\right) \varphi \times r$

where, $\varphi$ the central is angle in degree and $r$ is the radius of the curve. The design of monopoles is approximated to conventional PLPDA equations. The length of each monopole is bounded by upper and lower frequencies $f_{\max }$ and $f_{\text {min }}$ respectively. The wavelength of longest magnitude is computed using the wavelength equation (9).

$$
\lambda_{\max }=\frac{c}{f_{\min }}
$$

The magnitude of the longest element [16] having maximal length $L_{6}$ with width $W_{6}=0.86 \mathrm{~mm}$ is calculated using the equation (10).

$L_{6}=L_{\max }=\frac{\lambda_{\max }}{4 \sqrt{\varepsilon_{e_{2}}}}$

The apex angle $\alpha$ is evaluated [2] and follows as shown in the equation (11). $\alpha=\tan ^{-1}\left[\frac{1-\tau}{4 \sigma}\right]$

The active region bandwidth $B_{a r}$ and operating band width $B$ are computed [3] as shown in equations (12) and (13).

$B=\frac{f_{\max }}{f_{\min }}$

$B_{a r}=1.1+7.7(1-\tau)^{2} \cot (\alpha)$

The total number of monopole elements $N$ [3] can be determined by employing the equation as shown in (14)

$N=1+\frac{\log \left(B^{*} B_{a r}\right)}{\log \left(\frac{1}{\tau}\right)}$

The following are the steps adopted in developing the proposed antenna:

The antenna model is initialized by creating a FR-4 substrate with dielectric constant 4.4. The XY plane with $W_{s} * L_{s} \mathrm{~mm}^{2}$ area is created having thickness of $T_{s}$ is defined along $\mathrm{Z}$ axis

Copper ground plane with the thickness $T_{p} m m$ is developed below the substrate having the same dimensions of substrate and consigned as perfect $E$ boundary.

Micro strip line is placed on top of the substrate with dimensions $W_{f 50} * L_{f 50} \mathrm{~mm}^{2}$ and is excited by lumped port at one end. The width of the feed is chosen accurately to provide $50 \Omega$ impedance to match the source impedance. The other end is connected to quarter wavelength impedance transformer to match the load impedance.

The above technique enhances the bandwidth and reduces the reflection back to source.

\section{RESUlt AND DisCUSSION}

\section{A. Result:}

The simulations of the presented antenna design in this work have been implemented by means of the High Frequency Structure Simulation (HFSS) tool.

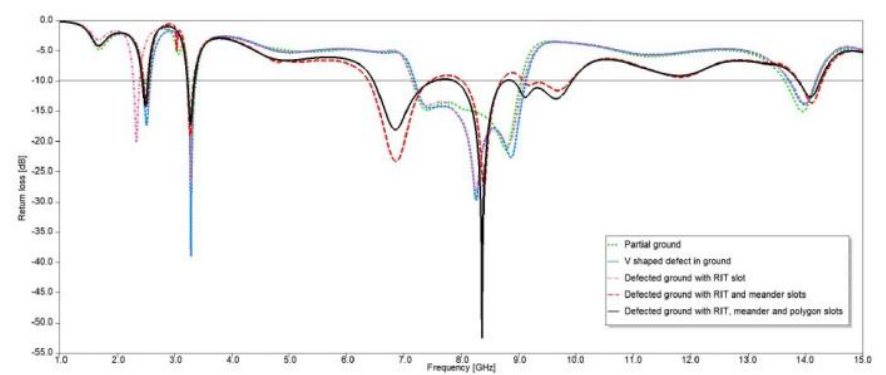

Fig. 4 Plot of VSWR vs frequency for several ground plane configurations

The outcomes of this simulation are examined to find defected ground structure comprised of various slot configurations as given in figure $1(\mathrm{c})$ to $1(\mathrm{~g})$. Computation of the impedance bandwidth is performed at a Return Loss (RL) 
of $-10 \mathrm{~dB}$. The simulated return loss characteristics and VSWR for different ground plane configurations over frequency is shown in figures 4 and 5 respectively.

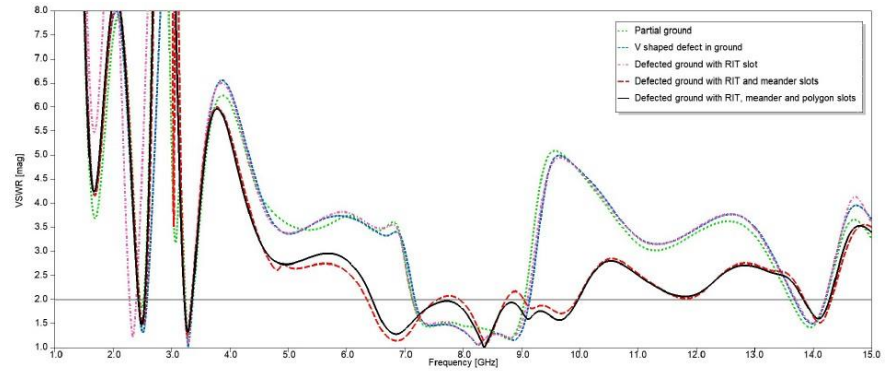

Figure 5. VSWR plotted against frequency for various ground plane configurations.

Defected Ground Plane: An antenna with defected ground plane having dimension $L_{g} \times W_{g}$ as shown in figure 1(c). Strip lines are used to realize on the bottom side of the substrate. In this techniques it degrades the low order frequencies and the return loss characteristics at $2.5 \mathrm{GHz}$ is poor having $S_{11}=-11 d B$.

V-shaped Defect in Ground Plane: Introduction of V-shaped symmetrical defect to the ground plane as presented in Fig. 1(d) not only alters the current distribution but also shows improvement in higher order resonance at $8.26 \mathrm{GHz}$.Using this technique the impedance bandwidth of $1.92 \mathrm{GHz}(7.18 \mathrm{GHz}$ to $9.12 \mathrm{GHz}$ )is achieved, it offers reduction in $R L$ by $6.71 \mathrm{~dB}$ and $13.05 \mathrm{~dB}$ at $2.5 \mathrm{GHz}$ and $3.3 \mathrm{GHz}$ respectively.

Defected Ground with RIT Slot: Integrating RIT slots in the DGP is shown in Fig. 1(e). Due to presence of narrow slot width $W_{\text {slot }}$ there is no significant change in the bandwidth at lower order frequencies below $4 \mathrm{GHz}$. The RIT slots are placed in the non-radiating region of DGP such that the radiation characteristics are unaltered.

Defected Ground with RIT and Meander Slots: Creating meander section in DGP with RIT slots is as shown in figure 1(f). The total geometrical length of the meander line in DGP supports resonance at $2.5 \mathrm{GHz}$ which plays a crucial role in reducing RL below $-5 d B$. Multiple slots in the meander line, improvise the impedance matching capability between $6.4 \mathrm{GHz}$ to $10 \mathrm{GHz}$, thereby lowering return loss $S_{11}$ less than $-10 d B$. The detailed dimension of DGP with RIT and meander slots are shown in figure 2 (a).

Defected Ground with Meander, RIT and Polygon Slots: The polygon (4-gon) slots along with both RIT and Meander as shown in figure $1(\mathrm{~g})$, possess an improvement of $80.2 \%$ in bandwidth at $8.36 \mathrm{GHz}(6.47 \mathrm{GHz}$ to $9.93 \mathrm{GHz})$ with good $\mathrm{RL}$ characteristics of $-52.57 \mathrm{~dB}$ in relation to variant described in Section III-B. The design dimension of the polygon slot is shown in figure 2(b).

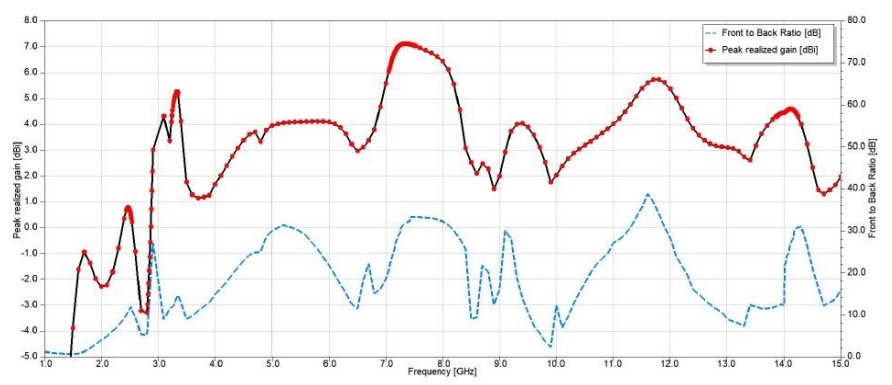

Figure 6. Realized gain (top curve) and FBR (bottom curve) plotted against frequency for antenna with DGP having RIT and meander slots along with polygon (4-gon) slot in curvilinear boom.

The peak attained against the antenna gain versus frequency is depicted in Fig. 6. The antenna suffers negative gains below $2.8 \mathrm{GHz}$ due to the lack of monopole reflectors having length more than $L_{6}$. This influences the radiation pattern in producing an omnidirectional pattern at frequencies below 2.8 $\mathrm{GHz}$ as presented in figure7 (i) and figure.8 (i). Higher order resonance is obtained from traveling waves with the increase in energy of propagating waves. Thus, compared to the length of a resonating element, those elements having greater lengths behave as reflectors while shorter lengths behave as directors. Due this there is a shift in the active region from the longest to shortest monopole elements. This results in the formation of a unidirectional end-fire radiation pattern having amplified gain in the forward firing direction as given in figure 7 (ii to vi) and figure 8 (ii to vi). The presence of curved reflector contributes in enhancing the forward realized antenna gain which results in few side lobes and back lobes. Reduction of side and back lobes effectively increases the Front-to-Back Ratio (FBR), as shown in Fig. 6. The H-plane pattern $\left(\phi=90^{\circ}\right)$ along $y-z$ axis suggests a E-plane pattern $\left(\phi=0^{\circ}\right)$ along x-z axis. A maximal realized gain of $7.1145 \mathrm{dBi}$ is achieved at $7.34 \mathrm{GHz}$ frequency. The comparison between the proposed antenna and the references are tabulated in Table II. The presented antenna is adept in bringing out better results when compared to the references [17]- [19] with reduced dimension and the number of elements.

Limitations: The proposed antenna design has a unidirectional radiation pattern, which limits its usage in wide band applications. This can be improvised and made multidirectional pattern with varying the antenna parameters.

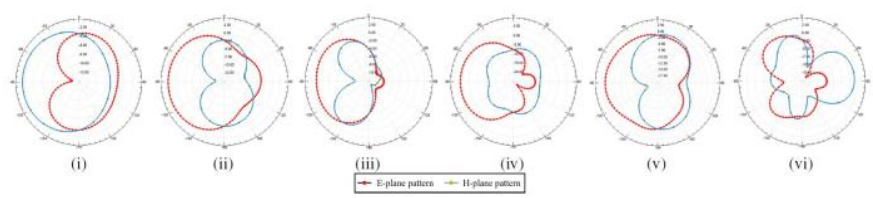

Figure 7. Simulated Radiation pattern (dB scale) in polar coordinates of DGP antenna with RIT, meander and polygon slots at (i) $2.49 \mathrm{GHz}$ (ii) $3.28 \mathrm{GHz}$ (iii) $6.84 \mathrm{GHz}$ (iv) $7.3 \mathrm{GHz}$ (v) $8.36 \mathrm{GHz}$ (vi) $14.09 \mathrm{GHz}$. 


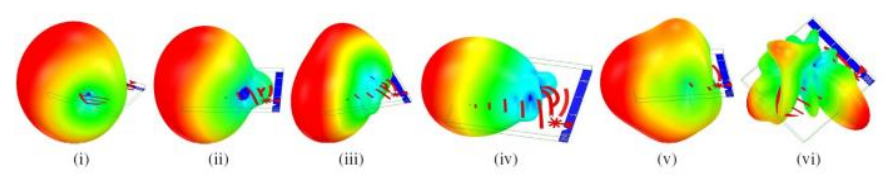

Figure 8. Simulated 3D Radiation pattern (magnitude scale) of DGP antenna with RIT, meander and polygon slots at (i) $2.49 \mathrm{GHz}$ (ii) $3.28 \mathrm{GHz}$ (iii) $6.84 \mathrm{GHz}$ (iv) $7.3 \mathrm{GHz}$ (v) $8.36 \mathrm{GHz}$ (vi) $14.09 \mathrm{GHz}$.

Table II. Contrast between the envisioned antenna and various printed Log-periodic patch antenna

\begin{tabular}{|c|c|c|c|c|c|c|c|c|}
\hline Methods & $\begin{array}{c}\text { Type of } \\
\text { Antenna }\end{array}$ & Dimensions & $(N, \tau, \sigma)$ & $\varepsilon_{r}$ & VSWR & $B_{r}$ & $\begin{array}{l}\text { Gain } \\
\text { (dBi) }\end{array}$ & $\begin{array}{c}\text { Feed } \\
\text { Location }\end{array}$ \\
\hline$[17]$ & PLPMA & $75 \times 25 \times 0.8 \mathrm{~mm}^{3}$ & $(12,0.91,0.35)$ & 2.2 & $<2.0$ & $1.74: 1$ & $6.5-9.5$ & $\begin{array}{l}\text { Longest element } \\
\text { side }\end{array}$ \\
\hline$[18]$ & LPMA & $520 \times 60 \times 1.27 \mathrm{~mm}^{2}$ & $(22,0.9,-)$ & $2.2 \& 10$ & $<2.5$ & $10.7: 1$ & 5.1 & $\begin{array}{l}\text { Shortest element } \\
\text { side }\end{array}$ \\
\hline [19] & LPMA & $88.5 \times 35 \times 2.413 \mathrm{~mm}^{3}$ & $(11,1.07,-)$ & 2.94 & $<2.0$ & $1.51: 1$ & 7.57 & $\begin{array}{l}\text { Shortest element } \\
\text { side }\end{array}$ \\
\hline Proposed & PLPCMA & $33.29 \times 29.15 \times 1.6 \mathrm{~mm}$ & $(6,0.865,0.12)$ & 4.4 & $<2.0$ & $1.53: 1$ & 7.11 & $\begin{array}{l}\text { Longest element } \\
\text { side }\end{array}$ \\
\hline
\end{tabular}

\section{A. Discussion}

Discussion: In the table II a comparison study between an envision antenna and various printed log periodic monopole antenna which are available is presented. It's evident from the tabulated results that the proposed antenna has shown better in miniaturization and $9.58 \%$ overall reduction in size with reduced number of elements is achieved. There is an improvement of $11.2 \%$ in gain parameter with VSWR $<2$. Further using commonly available FR4 substrate $(\varepsilon=4.4)$ its performance is better when compared with other PLPMA antennas which uses substrate having lower permittivity value.

\section{CONCLUSION AND FUTURE WORK}

This paper introduces an innovative method in achieving better results using compact PLPCMA antenna. Different type of ground plane effects is compared and demonstrated. The simulation outcomes show that a bandwidth of $100 \mathrm{MHz}$ $(2.44 \mathrm{GHz}$ to $2.54 \mathrm{GHz}), 120 \mathrm{MHz}(3.23 \mathrm{GHz}$ to $3.35 \mathrm{GHz})$ and $3.46 \mathrm{GHz}(6.47 \mathrm{GHz}$ to $9.93 \mathrm{GHz})$ have been achieved at resonating frequencies $2.49 \mathrm{GHz}, 3.28 \mathrm{GHz}$ and $8.36 \mathrm{GHz}$ respectively. The proposed antenna, at an operating frequency of $7.345 \mathrm{GHz}$ can obtain a peak realized gain of $7.1145 \mathrm{dBi}$ with a forward firing unidirectional end-fire radiation pattern. The envisioned antenna is capable of communicating to GSM device and able to transmit SMS to the mobile phone. Finally, the designed antenna mimics the miniature structure having bandwidth ratio of $1.53: 1$, an overall improvement of $9.5 \%$ in size reduction and $11 \%$ in gain is achieved respectively.

\section{References}

[1] R. H. DuHamel, D. E. Isbell. Broadband Logarithmically Periodic Antenna Structures. IRE National Convention Record. 1957; 5: 119128.

[2] D. Isbell. Log Periodic Dipole Arrays. IRE National Convention Record. 1960; 8(3): 260-267.
[3] R. Carrel. The Design of Log-Periodic Dipole Antennas.IRE International Convention Record. 1961; 6175.

[4] P. S. Hall. New Wideband Microstrip Antenna using LogPeriodic Technique. Electronics Letters.1980; 16(4): 127128.

[5] L. Giauffret, J. M. Laheurte, A. Papiernik. Study of Various Shapes of the Coupling Slot in CPW-fed Microstrip Antennas. IEEE Transactions on Antennas and Propagation. 1997: 45(4): 642646.

[6] G. Rafi, L. Shafai. Broadband Microstrip Patch Antenna with V-slot. IEE Proceedings Microwaves, Antennas and Propagation. 2004. 151(5): 435-440.

[7] M. A. Antoniades, G. V. Eleftheriades. A Compact Multiband Monopole Antenna with a Defected Ground Plane. IEEE Antennas and Wireless Propagation Letters. 2008; 7: 652-655.

[8] A. A. Salih, M. S. Sharawi. A Dual-Band Highly Miniaturized Patch Antenna. IEEE Antennas and Wireless Propagation Letters. 2016; 15: 1783-1786.

[9] M. M. M. Mirza, S. Dhage. A Miniaturized and Improved Antenna using Metamaterial. International Conference on Intelligent Computing and Control (I2C2), Coimbatore. 2017: 1-5.

[10]J. Tak, J. Choi. An All-Textile Louis Vuitton Logo Antenna. IEEE Antennas and Wireless Propagation Letters.2015; 14: 1211-1214.

[11] M. Keskilammi, M. Kivikoski. Using text as a meander line for RFID transponder antennas. IEEE Antennas Wireless Propagation Letters. 2004; 3: 372-374.

[12]K.ElMahgoub. Logo-antenna based RFID tags for advertising application. Appl. Comput. Electromagn.2010; 25(3): 174-181.

[13] W. Li, K. L. Chung, Y. Li. Characteristic Mode Design of Chanel-Logo Shaped Antenna. IEEE 3rd International Conference on Electronic Information and Communication Technology (ICEICT). 2020: 806-808.

[14]B. K. Subhash, A. Angulakshmi, K. Abhishek, Om Prakash Kumar, Tanweer Ali. A compact dual band BENZ logo antenna with staircase structured ground for 
millimetre wave (MMW) applications. International Journal of Innovative Technology and Exploring Engineering. 2019; 8: 123-129.

[15] T. Ali, A. Kavinamoole, S. B K, R. C. Biradar. A Toyota Logo Penta-band Antenna loaded with pi and inverted L-shaped Slots for Multiple Wireless Applications. 4th International Conference on Applied and Theoretical Computing and Communication Technology. 2018:31-35.

[16]C. Yu. Ultra wide band Printed Log-Periodic Dipole Antenna with Multiple Notched Bands. IEEE Transactions on Antennas and Propagation.2011; 59(3): 725-732.

[17]X. Wei, J. Liu, Y. Long. Printed Log-Periodic Monopole Array Antenna with a Simple Feeding Structure. IEEE Antennas and Wireless Propagation Letters. 2018;

[18] H. He, Y. Chen, S. Yang, G. Liu, S. Gao. Design of an Ultra-Wideband Array with Low Profile Log-Periodic Monopoles. International Applied Computational Electromagnetics Society Symposium, Bejing, China. 2018.

[19]A. T. Almutawa, G. Mumcu. Small Artificial Magnetic Conductor backed Log-Periodic Microstrip Patch Antenna IET Microwaves, Antennas and Propagation. 2013; 7(14): $1137-1144$.

[20]B. J. Kwaha, O. N Inyang, P. Amalu. The Circular Microstrip Patch Antenna-Design and Implementation. International Journal of Recent Research and Applied Studies. 2011; 8(1): 86-95.

[21] Madhukant Patel, Veerendra Singh Jadaun, Kanhiya Lal, PiyushKuchhal. Design of a High Gain Compact Circular Microstrip Patch Antenna for X-Band. International Journal of Engineering and Technology. 2018; 7(2.6): 168-170.

[22] Y. T. Lo, S. W. Lee. Antenna Handbook: Theory, Applications and Design. 2013; Springer Science and Business Media.

[23] L. C. Monticone, R. E. Snow, F. Box. Minimizing GreatCircle Distance Ratios of Undesired and Desired Signal Paths on a Spherical Earth. IEEE Transactions on Vehicular Technology. 2009; 58(9): 4868-4877.

[24]E. Dhanush Gowda, V. Nuthan Prasad. Design of LogPeriodic Monopole Array Patch Antenna for UWB Applications using Alphabetic Slots on Partial Ground Plane. IEEE International Conference on Electronics, Computing and Communication Technologies (CONECCT). 2020: 1-5.

[25] R. H. DuHamel, D. E. Isbell. Broadband Logarithmically Periodic Antenna Structures. IRE National Convention Record. 1957; 1: 119-128.

[26]Z.Mahlaoui, E. Antonino-Daviu, M. Ferrando-Bataller, H. Benchakroun, A. Latif. Frequency reconfigurable patch antenna with defected ground structure using varactor diodes. 11th European Conference on Antennas and Propagation (EUCAP), Paris. 2017:2217-2220.

[27]Z. Zhou, Z. Wei, Z. Tang, Y. Yin. Design and Analysis of a Wideband Multiple-Microstrip Dipole Antenna with
High Isolation. IEEE Antennas and Wireless Propagation Letters. 2016; 18(4): 722-726.

[28] Hattan Abutarboush, Omar F. Siddiqui, Muhammad Rizwan Wali, and Farooq Ahmad Tahir, " A Highly Bendable Log-Periodic Array Antenna for Flexible Electronics,Progress", In Electromagnetics Research M, Vol. 96, 99-107, 2020

[29] Mahesh Shankar Pandey and Virendra Singh Chaudhary, "Defected Star-Shaped Microstrip Patch Antenna for Broadband Applications, "Progress in Electromagnetics Research C, Vol. 118, 11-24, 2022

[30] Venkata A. P. Chavali and Amit A. Deshmukh, "Wideband Designs of Regular Shape Microstrip Antennas Using Modified Ground Plane," Progress In Electromagnetics Research C, Vol. 117, 203-219, 2021

[31] Nurhayati Nurhayati, Alexandre Manicoba De-Oliveira, Warangkana Chaihongsa, Bagus Edy Sukoco, and Akbar Kurnia Saleh, "A Comparative Study of Some Novel Wideband Tulip Flower Monopole Antennas with Modified Patch and Ground Plane," Progress In Electromagnetics Research C, Vol. 112, 239-250, 2021.

[32] David M. Pozar. Microwave Engineering. John Wiley and Sons, Inc. Publication. 2016. Static control systems and communication 4th semester, technologies.

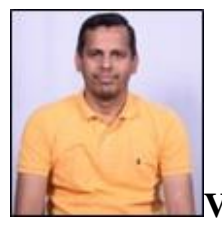
Digital Electronics and Communication from VTU, Belgaum in 2006. He is presently working as Assistant Professor in Department of Electronics and Communication Engineering, Ramaiah Institute of Technology, Bangalore. His research work is on Antenna Design, Wearable and Textile

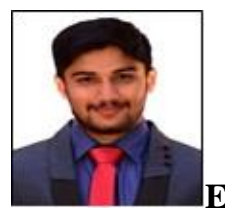
engineer in Robot Bosch from $2 y$ is wis a cas a software is in antenna and wireless technology with an immense gratitude and passion towards Body implantable antennas, Phased array systems, Meta-materials, Frequency independent and Fractal antennas, Lens antennas and Miniaturized antennas. He got his M. Tech degree from Ramaiah Institute of Technology. He has good publications in reputed Journals and conferences. 


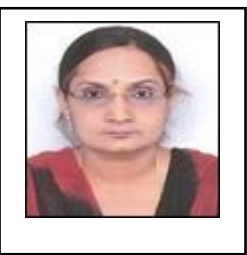

Dr. K Indira working as Professor in Department of Electronics and Communication, RIT from 2010. She received her Ph.D. from VTU in the year 2010; her area of research includes Image processing involved in Kannada character recognition. She has good publications in reputed journals and conferences. She has 30 years of experiences in Ramaiah Institute of Technology.

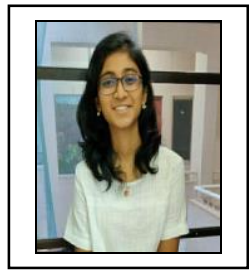

Ananya Kodukula is a student of Ramaiah Institute of Technology currently pursuing her 4th semester in the Department of Computer Science and Engineering; her areas of interest include spacecraft navigation and attitude control, satellite communications and astrophysics.

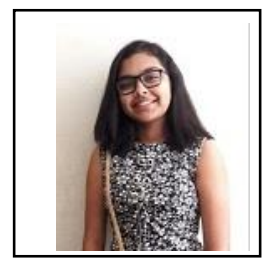

Bhavana B Rao is a student at Ramaiah Institute of Technology currently in her 4th semester of Electronics and Communication Engineering. Her areas of interest include Space science, robotic control systems and communication 4th semester, technologies.

\section{Contribution of Individual Authors to the Creation of a Scientific Article (Ghostwriting Policy)}

Venkatesh Nuthan Prasad was responsible for the design equations of antenna and mentor the student design parameter in parametric analysis.

Eshwar Dhanush Gowda held the responsibility of fabricating the antenna and testing in the Anechoic chamber

Krishnappa Indira took the role of strong literature survey of the curvilinear antenna and its design.

Ananya Kodukula held the responsibilities of simulation results and its validation

Bhavana B Rao had gone through the written document also helped in design equations finally minimize the plagiarism content.

Creative Commons Attribution License 4.0 (Attribution 4.0 International, CC BY 4.0)

This article is published under the terms of the Creative Commons Attribution License 4.0

https://creativecommons.org/licenses/by/4.0/deed.en_US 